\title{
EDUCACIÓN INTERCULTURAL COMO PROPUESTA EDUCATIVA CRÍTICA-REFLEXIVA: LIMITACIONES Y POSIBILIDADES EN CONTEXTOS DE INTERACCIÓN JUVENIL RURAL EN CHILE*
}

Carol Morales Trejos

\footnotetext{
* Resultado de Investigación Doctoral, Universidad de Santiago de Chile, Programa Ciencias de la Educación, mención en Educación Intercultural, periodo 2012-2015.

1 Docente de la Universidad de Costa Rica. carolgraciela.morales@ucr.ac.cr
} 


\section{RESUMEN}

Este capítulo presenta resultados de la investigación desarrollada en el Doctorado en Ciencias de la Educación, mención Educación Intercultural de la Universidad de Santiago de Chile; periodo 2012-2015. Como parte de las finalidades de este estudio se consideró analizar las posibilidades y desafíos del desarrollo de la Educación Intercultural en contextos de interacción juvenil rural, en función del actual desarrollo de las prácticas pedagógicas y los principales debates teóricos que se han desarrollado en torno a la temática abordada. Para tal fin, se realizó una investigación etnometodológica, cuyo enfoque teórico metodológico fue el hermenéutico-interpretativo, empleando entrevistas a profundidad a 14 docentes de seis Liceos municipalizados, ubicados en seis comunas rurales de la región metropolitana de Chile. Los resultados muestran en torno a los espacios educativos rurales la importancia de instalar una construcción de diversidad más posibilitadora del ser, que reconozca, valore e incorpore lo diverso desde la condición misma del ser humano, desde la vivencia, la riqueza y el aprendizaje. Las conclusiones de esta investigación enfatizan la necesidad de facilitar en la formación inicial docente y en la capacitación de docentes en ejercicio, el desarrollo de competencias interculturales, en un marco socioeducativo, cultural y político contemporáneo, que demanda de profesionales más reflexivos y críticos de la diversidad que configura el entramado social; personas profesionales que puedan hacer una realidad los principios de la educación intercultural.

Palabras clave: Educación rural, Docentes, Diversidad, Juventudes, Interculturalidad. 


\section{INTRODUCCIÓN}

Al iniciar este artículo, es importante precisar cómo es comprendida la educación intercultural, para lo cual se sigue a autores como Aguado, quien la define como:

Un enfoque educativo basado en el respeto y apreciación de la diversidad cultural. Se dirige a todos y cada uno de los miembros de la sociedad en su conjunto, propone un modelo integrado de actuación que afecta a todas las dimensiones del proceso educativo. Se aspira a lograr una auténtica igualdad de oportunidades/resultados para todos; así como la superación del racismo en sus diversas manifestaciones y el desarrollo de competencia intercultural en profesores y estudiantes. (1995, p.16)

Al considerar la interculturalidad como un enfoque que permite comprender la realidad educativa desde otras lógicas, cabe plantearse -siguiendo a Sagastizábal et al.- que "enseñar y aprender hoy significa poner en relación viejos y nuevos paradigmas, para ello, retomemos el concepto de sistema abierto en relación con la institución educativa" (2009, p.76), lo cual demanda desde la mirada intercultural, no desechar enfoques y/o paradigmas que han dado lugar a lo que hoy es la escuela como institución, sino integrar saberes, potenciar la diversidad sociocultural, articular los espacios educativos (escuela) y la comunidad, o bien, en contextos rurales articular espacios y territorios, desde una mirada crítica-transformadora.

La Educación intercultural, siguiendo el planteamiento anterior, y considerando a Escarbajal (2010), puede significar una buena alternativa a los modelos educativos monoculturales, porque, frente a la perpetuación de la cultura única; aspecto que ha caracterizado la educación, acepta la complejidad de cada ser humano y de su cultura y reconoce que todos somos pluricul- 
turales y podemos trabajar juntos para conseguir una sociedad democrática. En este sentido, la interculturalidad connotaría no solo la existencia de individuos y grupos culturales distintos (reconocimiento de la diversidad) sino también de inter-relaciones en planos de igualdad, sustentadas en el mutuo respeto (valoración e incorporación de la misma al proceso enseñanza-aprendizaje), que permiten plantearse la interculturalidad como proyecto nacional a nivel sociopolítico (Schmelkes, 2004; Whalsh, 2005).

Por consiguiente, la perspectiva intercultural comparte con el multiculturalismo (enfoque sobre el cual se han basado y gestionado las políticas públicas educativas actuales en su mayoría), el respeto hacia la diferencia y el hecho de instaurar la diversidad cultural como escenario de interacción para el enriquecimiento mutuo. Bajo esta premisa, se plantean enormes retos ciudadanos a fin de comprender adecuadamente la diversidad del ser humano y la comunicación intercultural en el contexto de las sociedades actuales. La educación intercultural propone, según Sagastizábal et al., "una mirada de la pluralidad cultural como una riqueza, aprecia el mundo de lo humano, en el mundo de la cultura, su pluralidad de expresiones, las valora como una sobre-abundancia" (2009, p.75).

Según las consideraciones anteriores, el objetivo de este artículo es mostrar la interculturalidad como un proyecto socioeducativo y político sólido, posteriormente develar tras el análisis del discurso docente en contextos de interacción juvenil rural en Chile, las limitaciones, pero sobre todo las posibilidades en el desarrollo de una propuesta en educación intercultural y los desafíos que esto conlleva a nivel educativo desde la mirada intercultural. 
A continuación se presentan las consideraciones metodológicas de la investigación citada, seguida de una breve discusión teórica de los principales referentes que considera este artículo, así como una síntesis de resultados y consideraciones finales del estudio realizado.

\section{DISCUSIÓN TEÓRICA}

\section{Modelos de Educación Intercultural: Propuesta}

Educativa Crítica-Reflexiva en la Comprensión de la

\section{Diversidad}

Al referir sobre la interculturalidad, no se puede dejar de lado hablar acerca del surgimiento del multiculturalismo, en tanto el origen discursivo como práctico de la interculturalidad se sustenta en muchos de sus planteamientos. Dietz (2003) señala los orígenes del multiculturalismo a un abanico amplio de movimientos sociales de los años sesenta y setenta que buscaban un horizonte político-social común. Estos movimientos, según el autor, surgen en el seno de las sociedades crecientemente post-industriales que se levantaron contra la institucionalidad establecida del Estado-nación, y es desde estos procesos de institucionalización programática que los movimientos multiculturalistas van generando su propia teorización académica, sobre todo para el contexto anglosajón.

Autores como Kymlicka (1996), Taylor (1993) y Habermas (2002) integran el debate multicultural y sus aportes se basan en la lucha por este reconocimiento de la diferencia, de la diversidad cultural, que al día de hoy siguen siendo trasladados a otras realidades sociales, educativas y políticas, dada su pertinencia, la cual -como señala Torres (2001) - radica en constituir temas como democracia, ciudadanía y educación los cuales no pueden tratarse aislados del tema del multiculturalismo. 
La incursión y el arraigo del multiculturalismo dentro de la pedagogía, lo marca -según Dietz (2003)- la evolución de los estudios étnicos, marcado en un primer momento por el autoestudio con fines de empoderamiento, practicado por las propias minorías étnico-culturales y por el surgimiento de los estudios culturales que critican los discursos académicos imperantes de la época, en el conjunto de las Ciencias Sociales y Humanidades occidentales. Aparece en los años ochenta y noventa el discurso reivindicativo como una novedosa aportación a la gestión de la diversidad educativa, asociado en su mayoría a querer resolver "problemas escolares" vinculados con la diferencia y la migración desde una interpretación multicultural (Dietz, 2003), aspectos que han sido las bases de muchas políticas educativas en relación a la gestión de la diversidad que se tensionan actualmente desde la mirada intercultural.

Seguidamente de que este debate se instalara en la educación, surge desde la antropología, un debate más complejo, que cuestiona la simplicidad de los discursos, y se empiezan a establecer debates sobre cultura y etnicidad avanzando ideas tradicionales agregando a dichos conceptos dinamismo e interrelación. Según Dietz (2003) surge una "antropología de la interculturalidad" que permite distinguir conceptual y empíricamente entre fenómenos inter-culturales e intra-culturales; es así como el principal aporte de la antropología al multiculturalismo y a la interculturalidad es la etnografía, consolidándose en tanto una "etnografía de la educación intercultural" que busca en primera instancia replantear y reiterar la estrecha relación que debe existir entre conceptualización teórica y realización empírica.

En este punto es clave referirse a la realidad social como un quehacer reflexivo que desde dentro, según el autor, recupera 
el discurso del actor social estudiado, y desde fuera, lo contrasta con su respectiva "praxis habituada". Dentro de este binomio teórico práctico que aporta la antropología a la educación intercultural, Dietz (2003) planea un modelo etnográfico tri-dimensional, que conjuga una dimensión semántica, una dimensión pragmática y una dimensión sintáctica, que permite comprender y complejizar la mirada desde el abordaje intercultural, de los cuales se rescata en este artículo la relevancia de la comprensión de los distintos fenómenos educativos relacionados a la diversidad juvenil rural, evidenciados en la práctica pedagógica como pase al acto.

A continuación, se consideran en primera instancia, aportes de distintas disciplinas en la conformación de la educación intercultural, posteriormente se avanza en la comprensión de la perspectiva intercultural en la educación según planteamientos de Escarbajal (2010), Aguado y Del Olmo (2009) y Abdallah-Pretceille (2006) que marcan los referentes sobre los cuales se sitúa la propuesta crítica-reflexiva considerada en este artículo.

Los autores Repetto (2003), Téllez (2008) y Gil (2008) coinciden en el aporte que distintas disciplinas como la antropología, la sociología, la psicología y la filosofía han otorgado a la conformación de la educación intercultural. A continuación una descripción breve de estos aportes:

Aportes de la filosofía. Desde esta disciplina -al igual que desde la antropología- se instaura el debate de una serie de conceptos claves, entre ellos, cultura y etnicidad. Uno de los mayores aportes de la filosofía planteado por Díaz, citado por Téllez (2008), ha sido la fundamentación de lo moral y las diferencias normativo-culturales desde una perspectiva fenomenológica. 
Aportes de la antropología. Constituyen los aportes más sobresalientes; desde esta disciplina se destaca el debate teórico complejo realizado en torno a conceptos como el de persona y de cultura, en tanto la idea de ciudadanía se encuentra vinculada a esta concepción de la persona, ser ciudadano que participa activamente en la creación de una sociedad más justa y equitativa; por otro lado el concepto de cultura, tomado de la antropología. Así mismo, un gran aporte de la antropología a la educación intercultural desde los planteamientos Del Olmo, citada por Téllez (2008), es a nivel metodológico, específicamente en el trabajo de campo nutrido desde la etnografía, que aporta una serie de métodos y estrategias que permiten realizar una coherencia entre la teoría y la práctica de la interculturalidad.

Aportes de la sociología. En las bases sociológicas, según Gil (2008), la educación intercultural se enriquece del modelo de sistema o estructural-funcional, que utiliza la noción de sistema como conjunto de partes interrelacionadas que tienden a la integración, y señala la necesidad de atender a la interrelación entre todas las dimensiones del medio social y educativo, destacando en este sentido autores como Ortega y Gasset (1914); así mismo nos ubica en la concepción de la persona situada en su contexto. Considerando este planteamiento sistémico Morgenstern, citada por Téllez (2008) desde la sociología, piensa que es importante instalar un debate que permita enfocar la educación intercultural como una necesidad actual en un mundo que excluye y a la vez concentra poder en algunos grupos minoritarios, complejizar la mirada, cuestionar cierta "naturalización" de algunos procesos a nivel social, como lo son la migración y la globalización, entre otros.

Aportes de la psicología. El enfoque intercultural en educación 
ha tomado aportaciones de tres líneas de indagación psicológica, según cita Gil (2008). En primer lugar, son relevantes los modelos cognitivos en Psicología Social, desde los que se han estudiado los procesos cognitivos involucrados en la formación y mantenimiento de actitudes, atribuciones y estereotipos, así como en la construcción de la identidad cultural individual y social. En este punto sobresalen autores como Allport (1979). En segundo lugar, destacan los aportes del paradigma histórico-cultural desarrollado por la psicología educativa dentro del cual sobresalen autores como Luria (1987), Vigotsky (1995), que analizan el papel que la cultura desempeña en la formación y desarrollo de las funciones psíquicas a través de la interiorización de los instrumentos culturales por parte de los/las estudiantes.

En último lugar, se encuentra la perspectiva cros-cultural adoptada en Psicología Social, que analiza los procesos de contacto entre culturas, mediante la formulación de dos conceptos claves; las fuerzas sociales y contacto interpersonal cros-cultural, estas dos ideas abordadas por autores como Aguado et al. (2003). Aunado a esto, un aporte de la psicología y de la pedagogía, lo constituye el enfoque socio-afectivo; el cual consiste en una metodología que enfatiza las actitudes y valores, que es participativa y fomenta la reflexión y el espíritu crítico tanto en docentes como estudiantes.

Una vez reconocidos los aportes de distintas disciplinas a la interculturalidad cuyo enriquecimiento tiende a ser recíproco, es importante señalar a Escarbajal (2010), quien considera una serie de enfoques que han dado paso a la interculturalidad, con dichos enfoques que el autor plantea, se ha respondido de diversas maneras ante la pluriculturalidad, abarcando distintos contextos geográficos; dentro de ellos, se identifica un modelo 
francés, que buscó abordar la inmigración y la discriminación laboral juvenil de trabajadores inmigrantes; el modelo británico, que al igual que en Estados Unidos se centró en políticas multiculturalistas que buscaban reforzar las identidades de las distintas comunidades y grupos sociales; el modelo alemán, el cual, igual que los anteriores atiende a las personas inmigrantes haciendo alusión al trabajador invitado o bien al obrero; el modelo holandés, por su parte aborda el tema de la inmigración de una forma más compleja e implementa un examen para estas personas sobre lengua y cultura nacional que fue implementado posteriormente por otros países, el modelo canadiense, tiene su paradigma en Toronto y busca abordar su diversidad cultural mediante la integración.

Sin embargo, en este punto señala el autor, los distintos modelos no lograron considerar en sus políticas de integración, el respeto y ejercicio de los derechos humanos, por lo que la alternativa intercultural se hizo evidente, proponiendo además del conocimiento de las culturas, su interrelación y la búsqueda de elementos en común que enriquezcan mutuamente. El autor, retomando a Banks (1997), señala la importancia de que la interculturalidad siga avanzando dentro del espacio educativo como un proyecto sociopolítico, crítico y transformador.

Escarbajal (2010) retoma a autores como García, Sáez y Escarbajal de Haro (1999) y señala de forma más precisa tres paradigmas que son los más destacados en el abordaje de la diversidad, que se relacionan con los discursos educativos planeados por Dietz (2003) en cuanto al sentido de educar, los cuales se citan a continuación:

Paradigma tecnológico: Su orientación es técnica y compen- 
satoria, porque de eso se trata. Desde este paradigma, la educación multicultural: de 'compensar' las deficiencias que traen los hijos de inmigrantes a nuestra sociedad, en este caso al alumnado inmigrante no le queda otra opción que integrarse en la cultura mayoritaria y sufrir procesos de aculturación.

Paradigma hermenéutico: Es un paradigma de reconocimiento gradual de la diversidad, pero no pone en cuestión la posición central de la cultura mayoritaria y dominante. Este es su mayor desacierto, sin embargo en este paradigma se acentúa el valor del diálogo y la comunicación intercultural, aunque este diálogo se desarrolla en unos parámetros alejados de la libertad, pues están mediatizados por el contexto sociocultural y por las condiciones sociales en las que se desarrolla la vida de cada estudiante de diversas culturas.

Paradigma crítico: Sostiene que todos los implicados en los procesos educativos: educadores, profesores, estudiantes, padres, madres, agentes sociales, etc., se comprometen en la interculturalidad, al tiempo que pretenden cambiar las condiciones sociales que cercenan las posibilidades de diálogo libre y abierto entre todas las culturas. Por ello, no se acepta a nivel formal el curriculum escolar como algo cerrado, sino que intenta cambiarlo para responder a los retos de la interculturalidad. Este paradigma es de especial importancia dentro de la tesis doctoral al constituir una base importante de la educación intercultural para comprender la diversidad juvenil rural y las prácticas pedagógicas docentes.

Al considerar los aportes, modelos y paradigmas que fundamentan esta propuesta educativa crítica, cabe señalar cuáles son las acciones puntuales en cuanto a la gestión de la diver- 
sidad juvenil rural, que desde esta mirada se pueden considerar. Autores como García y Sáez (1998) citados por Escarbajal (2010, p.143), consideran los siguientes principios orientadores de la educación intercultural, a saber:

a) Necesidad de adoptar una mayor sensibilidad hacia las diferencias existentes entre las personas de diferentes culturas, lo que posibilitará la mejora comunicativa entre los distintos grupos y culturas, estableciendo un enfoque curricular propicio a la reciprocidad y al consenso, eliminando prejuicios y estereotipos raciales, así como estimulando actitudes favorables a los miembros de las minorías y sus grupos de pertenencia.

b) Desarrollar competencias culturales, lingüísticas y comunicativas diversas, de modo que los valores propios de esa diversidad y el pluralismo cultural sean parte central del currículo formativo.

c) Ayudar a la emancipación cultural y social de las minorías, ampliando sus posibilidades sociales y laborales a través de su capacitación formativa y desarrollo de autopercepción positiva, lo que repercutirá de manera óptima en la configuración curricular y en la formación y capacitación de docentes.

Considerando que la educación intercultural se refiere a una verdadera exigencia de la propia naturaleza del acto pedagógico, se hace necesario procurar compromisos activos que se pueden traducir en acciones concretas en relación al reconocimiento, valoración e incorporación de la diversidad sociocultural entre todos los que conviven en un mismo espacio, como lo es el educativo. Escarbajal (2010, p.144) nos habla de ellos:

a) Reconocer y garantizar el derecho de las minorías étnicas a incorporar al sistema educativo, en particular, y a la so- 
ciedad en general, sus peculiaridades lingüísticas, religiosas y culturales, sin discriminación.

b) Incorporar y dar respuestas a los problemas de identidad cultural de las minorías desplazadas de su lugar de origen.

c) Atender las necesidades educativas especiales derivadas de la diversidad humana dentro de una misma cultura, es decir, de las minorías marginadas de cada cultura específica, así como responder a las necesidades de las nuevas minorías.

d) Promover el respeto por todas las culturas coexistentes y condenar las medidas políticas destinadas a asimilar a los emigrantes y minorías culturales a la cultura mayoritaria.

e) Plantear la educación intercultural como relevante para todos, no solo para personas inmigrantes o las minorías culturales.

f) Desarrollar esquemas conceptuales transculturales, para demostrar en la práctica educativa que el conocimiento es propiedad común de todas las personas, más allá de la cultura particular de un grupo concreto.

g) Tener el convencimiento de que ninguno de los problemas planteados por la diversidad étnica y cultural de la sociedad tiene una solución unilateral.

h) Aplicar los principios democráticos de justicia social favoreciendo la participación democrática.

i) Atender preferentemente a la calidad de las relaciones más que a los medios y apoyos puestos en juego.

j) Introducir nuevas estrategias didácticas y organizativas, tanto en las situaciones escolares como en la formación del profesorado y en las relaciones con los padres y la comunidad.

Hacer efectivos estos objetivos supone llevar a la práctica una verdadera educación intercultural, capaz de: 
Recoger la multiculturalidad para transformarla en encuentro rico $y$ formativo entre estudiantes, pero también entre las familias y el contexto social, una educación que transforme los estereotipos negativos y los prejuicios en actitudes positivas hacia el encuentro y la fusión con otras culturas, favoreciendo el desarrollo indiscriminado de las culturas minoritarias. Desde las premisas interculturales, una formación de este tipo debería comprender la educación para la escucha empática, es decir, predisponerse hacia una escucha profunda de los comportamientos, de las palabras y de las emociones de los interlocutores; el respeto intercultural, o sea, el desarrollo de la capacidad de descubrir a las otras culturas, y al mismo tiempo hacer posible la apertura del propio mundo a los otros; para la comunicación, con-seguir interpretar los mensajes para comprender cuáles de ellos son esenciales en la cultura del interlocutor, en su personalidad, en su rol y cuáles corresponden a aspectos contextuales. (Guidetti, 2009 citado por Escarbajal 2010, p.144)

Integrando los planteamientos realizados hasta el momento, comprender la diversidad sociocultural desde la educación intercultural, consiste en primer momento según Aguado (2005), descubrir lo que tenemos en común con las demás personas y lo que nos distingue, es decir reconocimiento de las diferencias; en segundo lugar, negociar objetivos e intereses que tenemos en común y las normas de comportamiento que nos van ayudar a lograr esos objetivos. En este punto el respeto y disposición hacia compartir y comprender el otro se hace indispensable.

Hernández (citada por Aguado y Del Olmo, 2009) propone para el abordaje de la diversidad tres aspectos claves, que permiten de forma puntual comprender esta propuesta crítico-reflexiva que constituye lo intercultural, a saber: 
1. Descubrir la diversidad, requiere aprender a reconocerla, es decir, identificar diferencias de nuestro entorno para entablar una posible relación, un intercambio.

2. Conocer el significado de la diversidad y valor social, supone la necesidad de distinguir las diferencias que tienen un significado social, ya que estas -según plantea la autora- son relativas, y no todas, ni siquiera las más evidentes son significativas, puesto que tiene distintos significados dependiendo del grupo, es decir, del significado que les confiere el contexto social. Este supuesto en la atención de la diversidad implica un desafío para desarrollar una actitud crítica para resolver los conflictos que nos plantea la vida cotidiana, o bien agenciar estrategias para aprender a convivir.

3. Apreciar la diversidad de forma positiva, indistintamente del valor que el grupo social le confiera a unas $u$ otras diferencias. Esto permitirá adecuar mejor la convivencia a la realidad social enriqueciendo el patrimonio de cada individuo.

Los supuestos anteriormente citados, llevan a considerar que la diversidad debe ser apreciada como una constante humana y forma parte de la vida misma. La heterogeneidad es la norma, no una excepción en cualquier grupo social en el que se dé una interacción y específicamente en la interacción juvenil rural como plantea la investigación a la que hace referencia este artículo. La educación intercultural en este sentido funge como hermenéutica, es decir, permite agenciar mecanismo teóricos y prácticos para su comprensión (Abdallah-Pretceille, 2006) valorando todo aquello que configura el mundo juvenil rural y las prácticas pedagógicas docentes en contextos rurales. 
Es importante precisar la propuesta de Abdallah-Pretceille (2006, pp.1-9) en relación al paradigma intercultural como mirada hacia la diversidad. En este caso se citan cinco líneas propuestas por la autora, que permiten avanzar en la comprensión de la diversidad como condición humana y formular políticas educativas e intervenciones educacionales más equitativas y atinentes a los requerimientos de las poblaciones jóvenes, las sociedades contemporáneas y lo intercultural. Esta propuesta consiste en avanzar en un primer momento del conocimiento de las culturas a un reconocimiento genuino del otro, desde una comprensión intersubjetiva, en la que la comprensión del otro exige un trabajo sobre uno mismo. En segundo lugar demanda reconocer que como individuos estamos siempre frente a fragmentos culturales, mezclas, mestizajes y trasgresiones, dado 26 que cada individuo tiene la posibilidad de expresarse y de actuar apoyándose no solo en sus códigos de pertenencia sino también en códigos de referencia libremente elegidos.

Como tercer punto, lo intercultural representa una práctica que busca comprender cómo se crea lo cultural en situaciones complejas. En cuarto lugar, comprender lo intercultural como hermenéutica, reconocimiento que recalca que ningún hecho es de entrada intercultural y dicha cualidad no es un atributo del objeto; solo el análisis intercultural puede conferirle este carácter: "es la mirada la que crea el objeto y no al contrario, lo intercultural reconstruye de la comprensión y de la acción el pensar en el encuentro del Otro no como el producto del conocimiento sino como un re-conocimiento (Abdallah-Pretceille, 2006, p.8). En último lugar, privilegiar en una propuesta intercultural la relación y la comunicación, abandonando el paradigma conceptual restrictivo de la cultura. 
La reflexión planteada en este apartado muestra la interculturalidad como una sólida propuesta en el abordaje de cultura rural y la diversidad, específicamente de las personas jóvenes quienes según Zebadúa (2008) son "sujetos sociales que dinamizan los escenarios de la globalización, los espacios multiculturales e interculturales, ya sea retroalimentando un proceso o impugnándolo mediante estrategias de participación alternas" (p.136).

\section{CONSIDERACIONES METODOLÓGICAS}

El objetivo general teórico de la investigación de la cual se extraen los datos que se muestran en este artículo, consistió en:

Analizar las posibilidades y desafíos del desarrollo de la Educación Intercultural en contextos de interacción juvenil rural, en función del actual desarrollo de las prácticas pedagógicas docentes y los principales debates teóricos que se han desarrollado en torno a la temática abordada.

Así mismo, en relación a los objetivos específicos, en este artículo se presentan resultados de un objetivo, que da respuesta al objetivo general anteriormente citado, correspondiente a los siguientes:

Conocer las condiciones que favorecen o dificultan el desarrollo de la educación intercultural dentro de las prácticas pedagógicas docentes en contexto de interacción juvenil rural, de la Región Metropolitana de Chile.

La fundamentación epistemológica permite dar cuenta mediante la construcción de un discurso científico hermenéutico, el fenómeno que se planteó estudiar, para lo cual se consideraron planteamientos de autores como Vasilachis de Gialdino (2009) y Zemelman (1992) respecto a los fundamentos ontológicos y 
epistemológicos de la investigación cualitativa. Aunado a esta fundamentación epistemológica, se contó con una fundamentación contextual, empírica y teórica empleada como insumo en la toma de decisiones metodológicas.

Considerando el método científico hermenéutico-interpretativo dentro del cual esta investigación se posicionó, se planteó un diseño de investigación etnometodológico caracterizado por la flexibilidad y la multiplicidad de escenarios y/o actores sociales que abarca, ya que corresponde a un estudio que selecciona un número menor de aspectos del fenómeno en estudio, aplicado a un número mayor de actores sociales dentro del fenómeno (Erazo, 2012).

Este diseño según Galindo (2009), presupone el reconocimiento de la capacidad reflexiva e interpretativa propia de cada actor social, aspecto que constituye el corazón mismo de la etnometodología, ya que la forma de conocimiento práctico es esa facultad que todo individuo posee y aplica en la rutina de sus actividades prácticas. La interpretación se plantea como algo indisociable de la acción, y al mismo tiempo algo compartido por el conjunto de los actores sociales. En este sentido la etnometodología sostiene que en las Ciencias Sociales todo es interpretación y que "nada habla por sí mismo".

Los escenarios de esta investigación lo configuraron cinco Liceos Politécnicos y uno científico-humanista, de la Región Metropolitana de Santiago de Chile, todos municipalizados, y ubicados en seis comunas consideradas rurales y distribuidas por grupos de ruralidad 1, 2 y 9 . Los sujetos de investigación fueron 14 docentes jefes de los cursos de tercero y cuarto medio, 7 de ellos con formación pedagógica y las 7 personas restantes con 
formación técnica variada. El primer contacto se realizó en la Dirección Regional de Educación de cada municipio; posterior a la autorización se contactó a las personas encargadas -directora o director de los establecimientos educativos- y al contar con el apoyo de la dirección, se procedió a buscar de forma individual a docentes jefes de tercero y cuarto medio, quienes de forma voluntaria brindaron sus conocimientos en relación al tema estudiado, resguardando las consideraciones éticas pertinentes en el proceso.

La principal técnica de recogida de información para desarrollar este estudio fueron las entrevistas en profundidad, específicamente se realizaron a cada docentes, que oscilaron entre los 45 minutos y una hora, cuya pertinencia metodológica radicó en "aprender sobre lo que realmente es importante en la mente de los informantes: sus significados, perspectivas y definiciones; el modo en el que los actores ven la realidad o en la que clasifican y experimentan el mundo..." (Canales, 2006, p.241).

En torno al procedimiento de análisis y validación de la información recolectada, para los propósitos de la investigación citada, se empleó el análisis de contenido, el cual, según Delgado y Gutiérrez (2007), es un tipo de análisis cualitativo que se centra en el análisis de las expresiones verbales tanto orales como escritas.

Retomando el modelo de desarrollo deductivo-inductivo del análisis de contenido tradicional propuesto por Mayring (2000) y el enfoque del método comparativo constante de Glaser y Strauss (1999), ambos citados por Cáceres (2003, pp.58-68), se establece una serie de pasos en el procedimiento de análisis de contenido, de los cuales el estudio doctoral consideró tres de los 
seis pasos propuestos; así mismo recogió los planteamientos sobre el desarrollo de la técnica análisis de contenido propuestos por Erazo (2012), que dieron lugar a cuatro pasos que a continuación se detallan:

Primer paso: Consideró el ajuste de la tabla de consistencia de la investigación, formulación de categorías y subcategorías, y definir las unidades de análisis. En este caso frases con sentido completo en un párrafo. Siguiendo a Briones (1988b), dichas unidades representaron el contenido significativo dentro del documento que sirvió para extraer resultados.

Segundo paso: En este paso se realizó propiamente la codificación progresiva de todo el corpus del contenido disponible, es decir, se identificaron en el texto las unidades de análisis para cada categoría y subcategoría que posteriormente se introdujeron en tablas descriptivas por docente.

Tercer paso: Corresponde al análisis descriptivo para el cual se consideraron tres etapas: la primera de ellas una descripción de primer nivel, seguida de una descripción de segundo nivel, etapas en las cuales se consideraron las semejanzas, diferencias, tendencias entre los discursos sobre las categorías y subcategorías, así como los criterios, grupos de ruralidad, origen geográfico y formación pedagógica o técnica empleados en las agrupaciones y comparaciones constantes que se realizaron. La tercera etapa de este paso, dio lugar a convertir las columnas de análisis de segundo nivel en texto dentro del capítulo de resultados, cuya presentación se estructuró considerando las preguntas de investigación.

Cuarto paso: Correspondió al análisis interpretativo etapa fi- 
nal del proceso; en este momento se integraron los hallazgos en el documento, para lo cual, empleando las últimas columnas de análisis descriptivo mencionadas anteriormente, se procedió a interpretar teóricamente considerando los objetivos tanto empíricos como teóricos de esta investigación, elementos centrales de la construcción teórica final, reflejada tanto en las conclusiones como en las proyecciones, consideraciones procedimentales que permiten asegurar la validez de la información que se obtiene, en tanto se relacionan con criterios de rigor científico importantes como la confiabilidad, validez, sistematización, consistencia, optimización de los procedimientos, y comunicabilidad.

\section{RESULTADOS}

\section{Interculturalidad: comprensión, posibilidades y}

\section{limitaciones en contextos de interacción juvenil rural}

A continuación se presenta parte de los resultados de la investigación a la que este artículo hace referencia, en lo que concierne al objetivo específico comprometido que evidencia cómo las personas docentes entrevistadas comprenden la interculturalidad, y cuáles son las condiciones que posibilitan o limitan el desarrollo de una propuesta intercultural a nivel educativo.

Las personas docentes de este estudio representan zonas rurales agrupadas por grado de ruralidad 1, 2 y 9 . Todas ellas, en un primer momento expresan de forma general desconocimiento en torno a la interculturalidad, sin embargo al seguir dialogando sobre el pluralismo cultural o sobre el multiculturalismo, surgen algunos referentes vinculados a la diversidad, la cultura y el intercambio, interesantes de considerar en este análisis.

A continuación se describen -desde la comprensión docen- 
te- las representaciones asociadas al desconocimiento y conocimiento sobre interculturalidad, dentro de las cuales se pueden apreciar nociones y principios de este enfoque educativo.

PMB1 manifiesta: "No, o sea, nunca se ha tocado como concepto en sí dentro del establecimiento...", al igual que PMB2: "Mira, para serte franco no me he informado, no me he informado bastante del tema intercultural, sé que parte de tu trabajo es ese, te agradecería si me puedes informar un poco más...”.

Por otra parte PMB3 expresa: "No, no he escuchado, tampoco he leído, pero lo he visto en la televisión un poco". Así mismo señala que en sus 30 años de experiencia docente tampoco ha recibido capacitación en estos temas que atañen a la interculturalidad como la cultura, la diversidad o el multiculturalismo; enfatiza: "No, por lo menos en media, nunca lo he visto, no sé, lo he visto en básica, en escuelas pequeñas unidocentes, lo veo, lo veo en la televisión, pero acá por lo menos no lo he visto", incluso cuando laboró en la zona urbana no se abordaron estos temas, lo cual se percibía como un hecho lejano.

Aunque PMB4 menciona desconocer el concepto argumentando: "Interculturalidad... así como término, no nunca lo he escuchado nombrar, no". Luego señala que lo ha escuchado, y como se puede apreciar, este ha estado asociado mayoritariamente a etnicidad, señala: "No... jah! Si no me equivoco eso lo he escuchado más pa'l Chile como pa'l sur, con las distintas etnias mapuches, más por ese sentido es lo que he escuchado ahora que me estoy acordando...".

Señala PMP1 que en estos temas vinculados al pluralismo 
cultural, multiculturalismo e interculturalidad "Nunca, nunca" ha recibido cursos ni capacitación, sin embargo asocia interculturalidad a identidad, argumentando: "Porque yo asocio la interculturalidad al origen del ser humano, de donde yo provengo, no qué función cumplo, de dónde yo provengo, en formar mi identidad" (PMP1).

PB2 considera que los Liceos agrícolas están tan enfocados en formar desde su especialidad, que no abordan temas vinculados a la educación intercultural: "Muy poco, prácticamente nada, o sea, más que nada, con solo lo que son colegios o liceos agrícolas más que nada estamos enfocados más a la parte netamente agrícola, ya". Por su parte PCT1, al escuchar la palabra interculturalidad, considera que hace alusión a: "Mira, yo lo puedo definir como una diversidad de culturas, una diversidad de gente con diferentes costumbres, perdón, gente que se agrupa en un lugar que son de distintas zonas por ejemplo, si lo podemos definir". Así mismo agrega que el constructo interculturalidad "Es que igual la cultura igual es un concepto amplio, porque acá lo puedo ver desde el punto de vista de la cultura, en cuanto... en cuanto a las personas sobre su conocimiento y todo eso...".

Para PMB3 la interculturalidad está asociada principalmente al intercambio cultural en contextos inter-étnicos y en educación básica, la preservación del mapudungún, señala: "He visto el cambio de estas escuelas, estas escuelas que han surgido, ponte en la parte rural y, que se les ha dado prioridad, suponte; yo lo ví el otro día en las noticias, en una escuela rural de Temuco, y se le había dado prioridad y le estaban enseñando y pasando el mapudungún, que es un dialecto que nosotros tenemos 
dentro de nuestro idioma castellano, entonces ellos hablaban de interculturalidad. Y lo otro que vi también en una noticia, fue que en una escuela, que no me acuerdo, se llamaba Escuela Paraguay... parece. Pero lo que me llama la atención es que todo es básico, como que todo resulta en la enseñanza básica, pero no se sigue en enseñanza media... los niños hacían festividades, ceremonias de ese país en esa escuela, siendo que habían niños chilenos también, entonces intercambiaban esas culturas...".

En lo que respecta al concepto de pluralismo cultural PMB4 reconoce que este puede estar asociado al espacio en el que las personas de distintos países comparten su cultura y también dentro de su curso a sus estudiantes, ya que estos tienen distintas formas culturales de expresarse, creencias distintas y costumbres. Por su parte PP2 añade que este constructo de interculturalidad, el cual ha leído, tiene varias definiciones y que no le ha quedado muy claro, en tanto su definición le parece "Muy rebuscada la... la definición".

PTT1 manifiesta que interculturalidad es aceptación del otro e incorporación de sus conocimientos, su cultura a la mía, realiza además el docente la siguiente diferenciación entre el multiculturalismo y la interculturalidad: "Se supone que la interculturalidad se diferencia de la multiculturalidad, porque la multiculturalidad implica toda esta... esta conjugación de culturas, de razas, de pensamientos, de ideas, pero soterradamente permite que exista la discriminación. A diferencia de la interculturalidad, que es exactamente lo mismo, pero implica una aceptación del otro y una integración de sus conocimientos, de su herencia ancestral, de su cultura a la mía, para que se forme una nueva cultura. Al final de cuentas, que comparte todas las demás. Eso es lo que yo entiendo...". 
Por su parte PB1, expresa haber escuchado hablar de la interculturalidad, sobre todo en la universidad cuando se abordó el tema de geografía latinoamericana: "Sí, sí, sobre todo en los últimos años, principalmente por los pueblos originarios, pero creo que eso se da principalmente en algunos sectores, más que en la generalidad, ya... una pincelada, quizás, dependiendo del área en la que uno esté, pero no, no así puesto sobre la mesa como tema principal, central no, no aparece".

En cuanto a la visión en el abordaje en Chile, PB1 considera que esta prevalece en el norte y sur de Chile, donde se cuenta con mayor presencia de pueblos originarios. La profesora señala que son años de retraso en esa temática que se vivencia a nivel educativo: "... Son años que no se ha trabajado, por lo menos en estos establecimientos..." aspecto que evidencia "que interculturalidad no es un tema que ha sido discutido de forma igualitaria en todo Chile a nivel educativo, no, para nada".

PB1 considera que según la diversidad de jóvenes con los que trabaja se puede hablar de relaciones interculturales y en este sentido introduce una categoría interesante: "Sí, sí, sí, yo creo que sí, dentro de su diversidad cultural o cultura juvenil, sí, sí, de acuerdo a los sectores económicos, geográficos, sí yo creo, que quizás no en términos interculturales a nivel de países, de pueblos, no, pero sí en su mínima expresión, digamos, así se podría hablar de una interculturalidad juvenil".

Avanzando en la descripción sobre la representación de la interculturalidad, las docentes y los docentes sujetos de esta investigación, reconocen la importancia de la propuesta intercultural y la valoran desde el intercambio juvenil, la potencialización 
de habilidades, las tradiciones y costumbres culturales. Sin embargo, reconocen limitaciones en su abordaje, asociadas principalmente a la gestión administrativa del establecimiento educativo, seguido de la poca disposición docente y estudiantil ante las temáticas diversidad, cultura, ruralidad e interculturalidad. Así mismo señalan que se llevan a cabo prácticas pedagógicas que consideran en alguna medida estos referentes, sobre todo en actividades extracurriculares que buscan favorecer la incorporación de la diversidad en el Liceo, pero no desde una conciencia intercultural, enfatizando que aún falta mucho por hacer, por lo cual se consideran aspectos que favorecerían el desarrollo de prácticas pedagógicas interculturales en el contexto educativo; la descripción se hace de manera integrada de los tres grupos de ruralidad, señalando algunas especificidades.

PTT1 manifiesta desde una perspectiva muy importante de recalcar: "Primero que nada, Chile es un país que tiene una amplitud geográfica súper importante, y tiene una cantidad de culturas originarias que son muy diversas; además es un país donde se está dando mucho esto de la inmigración, entonces es súper importante que nosotros empecemos a reenfocar la educación, a integrar estas culturas y que se empiece también a rescatar lo... nuestra propia cultura ancestral, o sea, no es posible que nosotros hayamos tenido una cultura tan importante como los mapuches y, que nadie sepa siquiera una palabra en mapudungún, ¿me entiendes? En el norte hay hermanos Aymaras, que entiendan que en el sur hay hermanos Mapuches, que tenían una cultura muy rica, con una cosmovisión importante... Entonces, los mismos peruanos vienen a aportar una cultura pero muy rica, ¿me entiendes? y, está llenándose, los colombianos también, que están llegando mucho, los haitianos también, han llegado mucho aquí... y están integrándose a la educación formal. 
Yo creo que es muy importante que se integre a los chiquillos, y que se desarrollen estas políticas interculturales". Estas consideraciones evidencian la importancia y la pertinencia de una propuesta educativa intercultural, basada en la reflexión crítica de temas asociados a la diversidad, la justicia social, la equidad, con el fin de erradicar asimetrías a nivel socioeducativo.

PMP2 valora que en torno a la promoción del diálogo y el encuentro con el otro en el espacio educativo, las personas jóvenes tienen una mejor actitud de apertura hacia el otro diverso; considera: "Yo creo que aún estamos en pañales en ese aspecto, y como sociedad todavía yo creo que no se acepta muy bien el... o sea, yo pienso distinto que tú, y hasta ahí no más llegamos, hasta a veces, de repente uno ya no tiene más... más relación con alguna persona, por lo mismo, porque es distinto... entonces yo creo que igual como sociedad nos cuesta un poquito aceptar las diferencias de opiniones, y los chiquillos yo veo que ellos son más abiertos al diálogo, a poder consensuar -de repente- ellos sus opiniones, más que un adulto...", elementos que evidencian la necesidad de interacción dentro del proceso educativo desde otras lógicas.

Aunado a lo anterior, PB1 y PB2 manifiestan que se evidencia la necesidad de que estos temas en torno a lo juvenil, la diversidad, la culturalidad, la ruralidad y la interculturalidad sean abordadas en la educación rural, ya que su no abordaje constituye una debilidad educativa; sin embargo la propuesta intercultural se visualiza como muy lejana.

Siguiendo la línea de favorecer espacios para el intercambio, aspecto importante para PCT1, manifiesta que el establecimiento educativo donde labora no ha propiciado espacios que pro- 
muevan la interacción juvenil que él ha observado. Se requiere: "Mira, yo... yo siento que el colegio no ha abordado la convivencia escolar, no ha abordado este problema, no hacen actividades para que los chiquillos se junten...”.

PB1 es la única docente del grupo de ruralidad 9, que hace alusión a la educación de pueblos originarios señalando que: "Antiguamente lo programaban, venía en cuarto medio, trabajo de países latinoamericanos y conocer algo de eso, ahora se mantienen algo en primero medio, pero así en los programas, no, cada establecimiento de acuerdo a la ubicación geográfica va adecuando y va incorporando ciertos elementos en relación a los pueblos originarios de Chile...”. Así mismo agrega la docente como posibilidad: “...Los establecimientos quizás pondrían integrarlos con un programa interno que fuera paralelo a lo que el Ministerio lo presenta, pero tampoco se hace".

Desde la visión de PB1 agregar a las prácticas pedagógicas el componente intercultural: "Yo creo que encajaría bien, que los chiquillos comprendieran el término cultura, que comprendieran que hay una gran diversidad, que no solamente existen diferencias entre ellos, de un mismo lugar, un mismo espacio...”.

PMP1 manifiesta: "Ahora cuando uno escucha y analiza, evidentemente, se pone a pensar que nosotros estamos en relación a eso, tenemos muchos alumnos que vienen con descendencia de otros lugares y lo pasamos desapercibido, pasa desapercibido; no se quiere reconocer, no le damos la importancia que tiene, no le damos la importancia que tiene... así como tampoco uno le da la importancia que tiene que tener el adulto mayor, los viejitos, los ancianos, ocurre como una cosa parecida", señalando en esta frase una actitud reflexiva al darse cuenta de la 
poca sensibilidad hacia la diversidad que se da en los contextos educativos; reconoce la importancia de valorarla y reconocerla.

Según PMB4 considerar la cabida en el espacio educativo de la educación intercultural: "Tendría que ser como a las distintas realidades, distintas culturas, no necesariamente tendría que ser a etnias u orígenes que uno tenga, sino que... a lo mismo, a los orígenes, pero a lo mejor las distintas personas tienen distintos orígenes, porque las familias son distintas, pertenecen, realizan una cultura diferente, porque tienen sus costumbres también, que sería parte de la cultura... entonces podríamos llevarlo como a esa área y potenciar en parte en la educación, esas diferencias se podría decir... sí, las costumbres, las creencias que tienen, ehhh, sí, eso".

Considera PCT1 que las prácticas pedagógicas que pueda incorporar la diversidad juvenil deben dar un salto, innovar, dejar atrás modelos educativos de los ochenta y noventa que actualmente no dan cuenta de la diversidad y la riqueza que se tiene en el Liceo; "Mira, como lo que te dije, hay que empezar a soltar un poco el, el plumón y el pizarrón y hay que empezar igual, a mejorar la práctica... innovar...", aspectos que denotan que muchos de los recursos que se requieren para realizar estas prácticas son más actitudinales que económicas, en tanto parten de la disposición docente de apertura a la diversidad y de actitud crítica y reflexiva.

PTT2 reflexiona sobre la diversidad juvenil lo siguiente: "Sí, es que normalmente la gente considera que tener alumnos diferentes o diversos les va a complicar el trabajo". Añade PTT2 y enfatiza que si las condiciones de la educación mejoran para el estudiantado, como docente también se crece. Menciona "que 
las condiciones de la educación sean mejores para ellos y así va creciendo uno también con el tiempo...".

Sobre cómo podría una persona docente integrar la diversidad cultural en su práctica pedagógica PTT1 señala, primero, según su criterio: "Planificando sus clases, desarrollando material que le ayude a integrar a todas las culturas. Tú sabes que la historia se enseña distinta en todos los países, por ejemplo, por qué no ver los dos puntos de vista, por ejemplo, de Perú y de Chile, en una clase".

PP1 manifiesta que es muy difícil que la persona docente se centre en todos los referentes culturales de los países del estudiantado que interactúa en la sala de clase, asumiendo de manera hipotética que exista variedad. Señala: "Es que es bien difícil, yo te pregunto a ti, ¿cómo lo harías? Porque tú realizas un plan educativo en base a la, a la biología, no sé, al, al criterio social de un país del perfil de un ciudadano, de un individuo que cumple con tus mismas características, con tus mismas tradiciones, con tu misma historia, entonces qué complejo sería elaborar un plan el que tú pudieras integrar, todo eso, o sea, tendría que más o menos conocer la historia o conocer el, el perfil sociocultural del país para integrarlo, tendría que ser como una magia, así como del arcoíris, o sea, yo sé, lo veo súper complejo...”.

En lo que se refiere a la valoración sobre las condiciones que limitan o favorecen el desarrollo de prácticas pedagógicas desde la mirada intercultural dentro del contexto educativo, PCT1 y PCT2, docentes del grupo de ruralidad 9, manifiestan que esta propuesta no debería ser una limitación en el espacio educativo; consideran que el intercambio juvenil es clave, aunque en el caso de PCT2 se le dificulte favorecerlo, plantea que al reconocer, valorar e incorporar la diversidad de las personas jóvenes, 
sus referentes culturales no deberían ser una limitación en el aprendizaje si hay disposición del alumnado, y no debería ser una restricción de la enseñanza si se enseña más allá de los contenidos, y se educa en valores. En este enseñar, hace énfasis a un compromiso docente, apelando incluso al significado que ella confiere a la enseñanza y a su identidad profesional.

Una de las condiciones que limitan que la interculturalidad a nivel pedagógico sea una realidad es la poca información y material para trabajar estos temas, y lo dispersa que se presenta la que existe. Señala PP2: "Hay poco, hay súper poco material, ahora que tú me hablas de eso, hay súper poco material preparado, que sea accesible para trabajar el, el tema. La otra vez me costó mucho, yo trato de trabajar hasta con videos con, me costó mucho pero encontré uno, me encontré uno que era como, me acordé por la palabra mosaico, que era como una especie de hexagonal, una figura geométrica que estaba dividida como en círculos o en figuras similares de colores...".

Aunado a lo anterior plantea PTT1 que una propuesta intercultural debe de plantearse desde una disposición ministerial, desde la política pública. Para que se pueda ejecutar a nivel educativo, "Tiene que partir por una política ministerial la cuestión, o sea, aquí lamentablemente si no te obligan a hacer algo, tú no lo hací... esa es la cultura del chileno, flojo... aquí parece que nunca leyeron esa frase que "tienes que hacer lo que te gusta y además te tiene que gustar lo que haces". Limitación que está asociada por parte de PTT1, PTT2 y PP2, docentes del grupo de ruralidad 2, a la resistencia a los cambios de un porcentaje de docentes, principalmente los más antiguos. A este hecho se suma la necesidad de instalar la propuesta como una política pública o bien institucional, ya que de lo contrario no se lograrán avances significativos a nivel educativo. 
Otro aspecto relevante de considerar como limitante es la falta de trabajo en equipo que se da en muchos Liceos, ya que el trabajo que se realiza en la actualidad tiende a ser aislado, acorde a lo que plantea PCT1 sobre la necesidad de planificación y coordinación institucional que permita que a nivel curricular las asignaturas se vinculen e interactúen mejor.

A modo de síntesis, se puede considerar que pese a que en cuanto a la representación a nivel cognitivo de la interculturalidad, todas las personas educadoras argumentan desconocimiento en mayor o menor porcentaje, a lo largo de sus discursos se evidencian aproximaciones teóricas al respecto, que señalan "el intercambio" y "la identidad cultural", como referentes fuertes en sus definiciones, seguido de una conciencia amplia de la importancia de implementar a nivel educativo una propuesta en educación intercultural, sus posibilidades y limitaciones.

En cuanto a la valoración de la interculturalidad, según las expresiones docentes y algunos comentarios específicos, no existe una conciencia docente de que en la práctica pedagógica se empleen nociones o principios de la mirada intercultural; las acciones que se realizan son gestionadas desde la experiencia, y algunas de estas ideas que plantea lo intercultural son abordadas desde el sentido común, o bien del saber pedagógico.

Tras la discusión de estos resultados, es importante mencionar siguiendo a Leiva (2011), que la mirada docente sobre la educación intercultural es vista desde dos perspectivas: una de ellas es la técnica-reduccionista y la romántica-folclórica. La primera, asociada a componentes étnicos y a condiciones migratorias; bajo esta perspectiva la propuesta intercultural se contempla como una respuesta a problemas lingüísticos, conductuales 
y de índole curricular. La segunda es vista como una utopía en la que se exalta el conocimiento cultural del estudiantado inmigrante dentro del centro educativo.

Dentro de las condiciones que limitan un abordaje intercultural a nivel educativo, se encuentra principalmente como tendencia discursiva la poca flexibilidad del curriculum, el factor tiempo, la necesidad de que iniciativas como estas sean consideradas y planteadas desde políticas públicas, la poca información al respecto; y como aspectos que favorecen, se puede citar la disposición docente y estudiantil en el abordaje de las temáticas que comprenden referentes socioculturales de la complejidad educativa.

Es importante aclarar que en lo que respecta al componente conductual, se rescatan prácticas pedagógicas en todas las comunas que recogen elementos que evidencian nociones y principios de la educación intercultural, asociadas al aceptar las distintas opiniones del estudiantado, facilitar espacios para el diálogo y la escucha, fomentar el respeto, el trabajo colaborativo, la motivación hacia el logro, la solución de conflictos; así como el facilitar la interacción juvenil, la valoración de la diversidad como riqueza en el aprendizaje. Entre otros aspectos, consideraciones que son visualizadas desde este estudio como espacios de posibilidades en la implementación de una propuesta educativa reflexiva-crítica desde la mirada intercultural.

\section{CONSIDERACIONES FINALES}

Las siguientes conclusiones se realizan retomando de forma analítica las condiciones educativas que facilitan y limitan la implementación de una propuesta en educación intercultural en contextos educativos rurales, vistas como oportunidades y desafíos en el espacio educativo rural referido. 
Una de las mayores posibilidades para desarrollar una propuesta intercultural dentro del contexto educativo rural, lo constituye la disposición docente hacia los temas abordados en las entrevistas que consideró la investigación a la que hace referencia este artículo, en tanto los acercamientos a las nociones y principios de la educación intercultural identificados dentro de las prácticas pedagógicas evidencian cómo la labor docente es re-significada desde la experiencia, prácticas pedagógicas valiosas que pueden potencializarse desde la mirada intercultural.

En la implementación de una propuesta educativa intercultural se requiere información y capacitación, como señala el profesorado, en tanto reconocen la necesidad e importancia de instalar esta mirada a nivel educativo no solo desde nociones étnicas, raciales o asociadas a procesos migratorios, sino desde lo que distingue a cada ser humano en relación a sus contextos $y$ vivencias.

De manera puntual, la propuesta intercultural se valora desde el intercambio juvenil en el marco de una "interculturalidad juvenil", la potencialización de habilidades, las tradiciones y costumbres culturales; sin embargo se reconocen limitaciones en su abordaje que se constituyen en desafíos desde las proyecciones de este artículo, que se vinculan en primer lugar, a la no conciencia a nivel teórico y práctico de que estas buenas prácticas docentes (Rodríguez, 2012) se realizan o se pueden realizar desde el enfoque intercultural, en tanto se carece de información, material y la guía necesarias para aprender lo que autores como Aguado (2005) o Leiva (2011) denominan competencias interculturales, que permitan generar cambios y mejores resultados educativos desde la equidad y la justicia social. Una de las posibles razones es, como señala PB1: "Interculturalidad 
no es un tema que ha sido discutido de forma igualitaria en todo Chile a nivel educativo...".

En segundo lugar, tanto a nivel ministerial (política pública), como a nivel institucional (gestión del centro educativo) y desde las corporaciones municipales (asignación de recursos) de manera interrelacionada se percibe que ciertas disposiciones se transforman en una "camisa de fuerza" que limita la ejecución de prácticas pedagógicas que permitan potenciar lo no escolar de lo escolar como señala Duschatzky y Sztulwark (2011), que son los espacios en los que realmente pasan las cosas importantes y significativas, en tanto se maneja un doble discurso a nivel curricular que abarca la flexibilidad versus la rigidez, que poco a poco provoca que se aprenda a gestionar lo educativo desde la poquedad pedagógica como señala Baquero (2001) y no desde lo que hay como potencial que genere otras posibilidades de ser y estar en los establecimientos educativos, espacios que aún convocan a las personas jóvenes rurales. En este sentido, promover políticas públicas, actividades institucionales y proyectos municipales que incluyan de manera activa a las personas de la comuna, estudiantes, docentes, líderes comunales, se hace relevante dentro de la propuesta de interculturalizar el curriculum escolar, para encontrar un camino, una respuesta ante la imposibilidad que señala PCT2 al manifestar: "Todavía no le veo cómo podría ser, no sé, cómo podría ser, cómo encajar dentro de todas las exigencias programáticas que tiene el Ministerio respecto del establecimiento y que homogeniza para todos igual, para todos igual...".

En tercer lugar, se pude considerar siguiendo a Rehaag (2010) como otro factor que limita, en tanto no está presente y que a la vez se configura en un desafío a nivel institucional, 
es el de favorecer el desarrollo de una cultura de la diversidad, aspecto que permitiría que a nivel educativo se evidencie una perspectiva intercultural, para lo cual se requiere y demanda de un trabajo colaborativo entre municipios y establecimientos educativos, considerando a sus distintos actores.

La reticencia al cambio de muchas personas docentes, junto con el desconocimiento de lo intercultural, la diversidad, el multiculturalismo, pluralismo cultural y sobre todo de cómo operacionalizar estas categorías a nivel educativo, en tanto como señala Betancourt (2004), aún no se aprende en la interacción a pensar de nuevo las relaciones, en estos contextos rurales, constituye una cuarta limitación y un espacio de posibilidad para el desarrollo de una propuesta intercultural en el espacio educativo.

Tras las consideraciones anteriores, cabe enfatizar sobre las posibilidades, de forma específica en torno a los espacios educativos rurales en los que una propuesta intercultural tendría cabida. Se encuentra en primer lugar como desafío, instalar una construcción de diversidad más posibilitadora que reconozca, valore e incorpore lo diverso desde la condición misma del ser humano, es decir que abarque además de los referentes étnicos y raciales, los distintos sentidos de pertenencia e identidad cultural que las personas tanto en contextos rurales como urbanos, nacionales y extranjeros poseen no como referentes estáticos sino desde la vivencia, la riqueza y el aprendizaje. Aunado a lo anterior se requiere agenciar procesos de capacitación en que la competencia social hacia la diversidad -como señala Aguado (2003) - sea instalada a nivel curricular.

El innovar la práctica pedagógica, es en segundo lugar un espacio para lo intercultural, en tanto permita flexibilizar el pensa- 
miento hacia nuevas formas de resignificar la teoría y la práctica dentro de los procesos de enseñanza y aprendizaje en contextos rurales.

En tercer lugar, potenciar los espacios para la reflexión pedagógica, que están ya instalados en los establecimientos educativos estudiados, desde el reconocimiento, valoración e incorporación que propone el modelo de actuación intercultural de manera interrelacionada, facilita una nueva comprensión de la complejidad educativa. En este caso, en contextos de interacción juvenil rural.

En cuarto lugar, se debe aprovechar que existen habilidades docentes en contextos de interacción juvenil rural, hacia la escucha, la disposición al diálogo, al trabajo en equipo y empatía, como nichos a fortalecer desde una perspectiva crítica y reflexiva en la que la brecha entre los saberes teóricos y pedagógicos/ experienciales se disminuyan cada vez más.

Dentro de las sociedades multiculturales y pluriculturales contemporáneas, los espacios educativos son cada vez más heterogéneos y en este escenario las posibilidades de intervención de la interculturalidad como enfoque pedagógico es relevante, y se presenta como su principal desafío el instalar en la reflexión docente un enfoque socio crítico que permita en los procesos teóricos y operativos de la práctica pedagógica, la articulación de las nociones y principios de la educación intercultural desde el reconocimiento, valoración e incorporación de la diversidad considerando un accionar consiente y planificado, aspecto que constituye uno de los aportes de esta investigación en perspectiva intercultural. 
En síntesis, y como un espacio de posibilidades, se puede afirmar que pese a existir un desfase entre la teoría y la práctica de la interculturalidad, y aunque persista cierta idea de compensación educativa en el concepto de educación intercultural (Dietz, 2003), la interculturalidad desde el actual desarrollo de las prácticas pedagógicas hace su aparición como un hecho inconsciente, que se hace consciente al poder contar con los espacios apropiados para visualizarla como una alternativa pedagógica para construir un sistema educativo más solidario y posibilitador del ser. Se requiere entonces a nivel educativo rural, de espacios de reflexión que permitan que las actividades interculturales que se consideren desarrollar, surjan de un intento consciente y planificado de aprender a convivir en la diversidad como algo absolutamente ineludible y valioso.

Los establecimientos educativos estudiados, pese a estar supeditados a las disposiciones y lineamientos Ministeriales, tienen en las reuniones de profesores o reflexión pedagógica, un espacio potente para implementar la propuesta intercultural desde un enfoque sociocrítico y transformador de la realidad que les interpela, en un primer momento desde la comprensión de la complejidad educativa y de brindar un espacio para la formulación de preguntas más que de la búsqueda temprana de respuestas, en un segundo nivel, en hacer consiente dentro de sus prácticas pedagógicas las nociones y principios interculturales que las configuran avanzando hacia una mirada crítica, reconociendo, valorando e incorporando la diversidad dentro de los procesos operativos de la práctica pedagógica. Dicho avance epistémico permitirá un paso a la acción y constituiría la realización de prácticas pedagógicas interculturales, y por ende de una genuina puesta en práctica de la interculturalidad. 


\section{REFERENCIAS BIBLIOGRÁFICAS}

Abdallah-Pretceille, M. (2006). El paradigma intercultural como mirada hacia la diversidad. Actas Congreso INTER: Madrid: Servicio Publicaciones UNED. Intercultural. Recuperado de http://www.uned.es/congreso-inter-educacion-intercultural. (16 junio 2016)

Aguado, T. (1995). Un modelo de Orientación para la comprensión y competencia multiculturales. Revista Española de Orientación y Psicopedagogía, 6(10), 105-111. ISSN: 11397853. ISSN-e: 1989-7448.

Aguado, M. (2005). Educación Intercultural: Una propuesta para

la transformación de la escuela. Madrid, España: Ministerio de Educación y Ciencia.

Aguado, T. (2003). Pedagogía intercultural. Madrid: McGraw-Hill. Aguado, T., Ballesteros, B., Malik, B. \& Sánchez, M. (2003). Educación intercultural en la enseñanza obligatoria: prácticas escolares; actitudes y opiniones de padres, alumnos y profesores; resultados académicos de los estudiantes de diversos grupos culturales, en Revista de Investigación Educativa (RIE), 21(2), 323-348. ISSN: 0212-4068. Recuperado de http://www.uned.es/grupointer/articulos.html\#sthash.vTNUGtiH.dpuf

Aguado, T. \& Del Olmo, M. (2009). Educación Intercultural. Perspectivas y propuestas. Madrid, España: Editorial Universitaria Ramón Areces, Universidad Nacional Educativa a Distancia (UNED).

Aguado, T. (2011). El enfoque intercultural en la búsqueda de buenas prácticas escolares. Revista Latinoamericana de Inclusión Educativa, 5(2), 23-42. ISSN: 0718-7378 (edición electrónica). ISSN: 0718-5480. Recuperado de http://www. uned.es/grupointer/articulos.html\#sthash.vTNUGtiH.dpuf Baquero, R. (2001). La Educabilidad bajo Sospecha. Cuadernos de Pedagogía 9. Universidad Nacional de Quilmes. 
Cáceres, P. (2003). Análisis Cualitativo de Contenido: Una alternativa metodológica alcanzable. Revista Psicoperspectivas de la Escuela de Psicología, (2), 53-82. Facultad de Filosofía y Educación Pontificia Universidad Católica de Valparaíso.

Canales, M. (2006). Metodologías de Investigación Social. Introducción a los oficios. Santiago, Chile: LOM Ediciones.

Delgado, J. \& Gutiérrez, J. (2007). Métodos y técnicas cualitativas de investigación en Ciencias Sociales. Madrid: Síntesis.

Dietz, G. (2003). Multiculturalismo, interculturalidad y educación. Una aproximación antropológica. Granada, España: Editorial Universidad de Granada.

Duzchatzky, S. \& Sztulwark, D. (2011). Imágenes de lo no escolar, en la Escuela y más allá. Tramas Sociales, 66. Buenos Aires, Argentina: Paidós.

Erazo, S. (2012). Metodologías de investigación Cualitativa. (Material mimeográfico del curso). Universidad de Santiago de Chile. Programa de Doctorado en Educación, Mención en Educación Intercultural.

Escarbajal, A. (2010). Interculturalidad, Medición y trabajo colaborativo. Madrid, España: Ediciones Narcea, S.A.

Fornet-Betancourt, R. (2004). Reflexiones de Raúl Fornet Betancourt sobre el concepto de Educación Intercultural. Coordinación General de Educación Intercultural y Bilingüe. Secretaría de Educación Pública. México, D.F: Editorial, Consorcio Intercultural.

Galindo, J. (2009). Comunicología, etnometodología y comunicometodología: la comunicación como acción y como representación reflexiva constructiva. Razón y palabra, 67. ISSN-e: 1605-4806.

Gil Jaurena, I. (2008). El enfoque intercultural en la educación primaria: una mirada a la práctica escolar. (Tesis doctoral). Madrid, España: Universidad Nacional de Educación a Dis- 
tancia. Facultad de Educación:

Habermas, J. (2002). La inclusión del otro. Estudios de teoría política. Barcelona: Paidós.

Kymlicka, W. (1996). Ciudadanía multicultural. Una teoría liberal de los derechos de las minorías. Capítulos 1, 2, 3 y 8 . Barcelona: Paidós.

Leiva, O. (2011). La Educación Intercultural en una encrucijada de caminos: reflexiones pedagógicas para la construcción de una escuela intercultural. Revista Digital del Centro del Profesorado Cuevas-Olula (Almería), 4(7), 43-56. Espiral. Cuadernos del Profesorado.

Rehaag, I. (2010). La perspectiva intercultural en la educación. El Cotidiano, (160), 75-83. Universidad Autónoma Metropolitana Unidad Azcapotzalco: D.F., México. Recuperado de http://www.redalyc.org/articulo.oa?id=325127660009. 16 de junio de 2016

Repetto, E. (2003). La Orientación Intercultural: Problemas y Perspectivas. Orientación y Sociedad-2001/2002, (3). Madrid, España: Universidad Nacional de Educación a Distancia (UNED).

Rodríguez, H. M. (2012). Una definición original de "buenas prácticas". Fortalezas y debilidades de la adopción del término en Educación. Santiago de Compostela, España: Universidad de Santiago de Compostela.

Sagastizábal, M., Perlo, C., Pivetta, B. \& San Martin, P. (2009). Aprendery enseñar en contextos complejos. Multiculturalidad, diversidad y fragmentación. Buenos Aires, Argentina: Centro de Publicaciones Educativas y Material Didáctico.

Schmelkes, S. (2004). La educación intercultural: un campo en proceso de consolidación, 9(20), 9-13. RMIE, Ene-Mar 2004. Taylor, C. (1993). El multiculturalismo y la política del reconocimiento. México D.F.: FCE. 
Téllez, J. (2008). Educación Intercultural. Miradas Multidisciplinares. Gobierno de España: Catarata Ministerio de Educación y Política Social y Deporte.

Torres, C. (2001). Democracia, educación y multiculturalismo: dilemas de la ciudadanía en un mundo global. Capítulos 6 y 7 . México D.F.: Siglo XXI.

Vasilachis de Gialdino, I. (2009). Los fundamentos ontológicos y epistemológicos de la investigación cualitativa. Forum Qualitative Social Research, 10(2), Art. 30. Buenos Aires, Argentina. Recuperado de : http://www.qualitativeresearch.net/index. php/fgs/article/view/1299/2778

Walsh, C. (2005). La interculturalidad en la educación. Ministerio de Educación. Lima-Perú: Dirección Nacional de Educación Bilingüe Intercultural (DINEBI).

Zebadúa, J. (2008). Culturas Juveniles en contextos globales. Estudio sobre la construcción de los procesos identitarios de las juventudes contemporáneas. Veracruz: Universidad de Granada y Universidad de Xalapa.

Zemelman, H. (1992). Los horizontes de la razón I, uso crítico de la teoría; Dialéctica y apropiación de presente. México: Editorial del Hombre. 